\title{
Thomas Erastus oor die struktuur van die gemeenskap*
}

\author{
AD Pont
}

\begin{abstract}
Thomas Erastus on the church, the rulers and the community

In this, largely descriptive paper, the views of Thomas Erastus $(1520-1583)$ of Heidelberg, are discussed. Erastus' views on the church, the rulers and the community are put forward in his Treatise Explicatio gravissimae of 1568-69, published in 1589. It is clear that Erastus depends on the Zurich covenant-theology in his view that the community is essentially a Christian community ruled by the pius magistratus. In this community the church does not appear as a separate coetus or societas, but is ruled by the godly prince who rules according to God's law. Erastus' view gained popularity in the ecclesia Anglicana and was, to a certain extent, also a plea for the divine rights of kings.
\end{abstract}

\section{INLEIDENDE OPMERKINGS}

Dit is duidelik dat die sestiende eeu ' $n$ tyd was waarin baie dinge wat uit die verlede gestam het, in duie gestort het en dat op baie vlakke nuwe insigte na vore gekom het. Dit was nie net op die kerklik-godsdienstige vlak waar, danksy die arbeid èn insigte van Martin Luther, geweldige veranderings plaasgevind het nie, maar ook op die staatkundig-politieke èn kulturele vlak, is baie veranderings te konstateer. Die bewegings van die Renaissance en die Humanisme, verwant aan mekaar en tog verskillend van inhoud, die opkoms van die nasionale state, die verbrokkeling van die godsdienstig-kerklik-bepaalde eenheidstruktuur en kultuur van die Middeleeue, dui alles op die veranderings wat besig was om plaas te vind. In hierdie tyd is dit opvallend dat heelwat aandag gegee is aan die vraag van die struktuur van die gemeenskap, die omskrywing van die kerk en die bepaling van die verhouding van die kerk tot die burgerlike owerheid. Dit was veral in die Reformatoriese beweging van groot belang, want die verwerping van die oppergesag van die pous van Rome, het verreikende konsekwensies gehad.

-Referaat gelewer voor die Kerkhistoriese Genootskap van die Nederduitsch Hervormde Kerk op 20 November 1984. 
In hierdie uiteensetting word 'n oomblik gekyk na die opvattings van Thomas Erastus, professor in die Geneeskunde aan die Universiteit van Heidelberg in die Kurpfalz van 1558-1580. Dit dan veral in sy samehang met die denke van die Zürichse hervormers.

\section{DIE MIDDELEEUSE OPVATTING}

Die Middeleeuse wêreld word bepaal deur die grondliggende gedagte dat daar net één, enkele staat is, met die Christendom as basis en die pous van Rome as die sigbare hoof daarvan. Dit is die civitas Dei, gedomineer deur die dogma van die plenitudo potestatis van die pous (Fremantle 1963: 69-70). Immers in die Middeleeue bestáán daar nié so iets soos 'n 'staat', in die sekulêre sin, soos óns dit ken nie. Dáár is, om dit só te sê, die allesomvattende kerk die staat en selfs die Heilige Romeinse Ryk van die Duitse volk wat so kenmerkend van die Middeleeuse situasie is, is nie veel meer as 'n poging om die civitas Dei te realiseer, met die pous as opperheer, nie. Dit hang saam met die hele Roomse kerkbegrip wat die kerk as heilsinstituut en as die voortdurende inkarnasie waardeer èn ook as 'n organisasie, 'n omvattende maatskaplike orde (Van der Linde 1948: 91-99). Dié allesomvattende kerk, is die eenheidsbasis van die Middeleeuse teokratiese corpus christianum. Die kinderdoop is hier die primêre voorwaarde vir toetrede tot hierdie gemeenskap net soos ekskommunikasie die teenoorgestelde daarvan is. Hierdie Middeleeuse corpus christianum met die pous as die hoogste gesagdraer (vgl Bonifatius VIII se bul Unam Sanctam, 1302) was ten alle tye ' $n$ eenheid en JN Figgis (1960: 57) is seker korrek as hy stel:

'The medieval struggles between Popes and Emperors are wrongly regarded as a conflict between Church and State, if by that is meant the relations between two societies. The medieval mind, whether clerical or anti-clerical, envisaged the struggle as one between different officers of the same society, never between two separate bodies;...'

Die basis van die Middeleeuse opvatting van die één gemeenskap, is die eenheidsopvatting van die Romeinse Ryk met sy basis die Romeinse regsisteem. Dié opvatting van 'n eenheidsgemeenskap het dwarsdeur die Middeleeue gegeld en die meer federalistiese gemeenskapsordening wat deur die konsiliêre beweging en, onder andere, deur Nicolaas van Cusa, $1400-1460$, in sy De concordantia catholica 1433, gestel is, kon nie daarin slaag om dit te verdring nie. Hoewel gedurende die Middeleeue die gedagte gestel is dat die burgerlike staat 
óók aansprake en regte het, is die opvatting dat sowel die burgerlike gemeenskap as die kerk 'n perfecta societas sibi sufficiens is, nié werklik aanvaar nie. Die Middeleeuse gemeenskap was die corpus christianum, 'n gemeenskap wat nie deur fisiese of politieke grense beperk was nie. Sy grense het gelê waar die grense van die pous se gesag geleë was. Dié Middeleeuse gemeenskapsiening as ideaal èn as werklikheid, word egter in die sestiende eeu deur die al groter aanvaarding van die gedagte van die nasionale staat en die Kerkhervorming se opvattings, finaal vernietig.

\section{ENKELE OPMERKINGS OOR DIE OPVATTINGS VAN DIE KERKHERVORMING}

Dit was veral Martin Luther wat die Middeleeuse corpus christianumopvatting finaal vernietig het. Dit was 'n genadeslag, want vanweë die onvermoë van die pouse en die keisers om tot 'n soort vergelyk te kom, was die hele omvattende raamwerk al aan 't wankel. As Luther die Corpus iuris canonici by die Elstertor van Wittenberg op 10 Junie 1520 verbrand, dan verbrand hy op 'n simboliese manier al die aansprake van die pous èn die kerk op die oppergesag in die corpus christianum. Dit beteken óók die verwerping van die Roomse leer van die twee swaarde wat die pous sou dra. Volgens Luther is daar net één swaard en dié word die Godvresende vors, wat deur die kerk van advies bedien word, gedra. Die oppergesag in die nasionale staat, wat in essensie 'n Christelike staat is waar slegs één godsdiens toegelaat kan word, lê in die hande van die vors. Selfs die seggenskap, die wetgewende bevoegdheid oor die kerk, kom die vors toe. Nou is die civitas Dei, om dit so te stel, die burgerlike staat, want die kerk, vir sover dit 'n koninkryk is, is 'n koninkryk wat nié van hierdie wêreld is nie. Luther se opvatting is dat alle dwingende gesag in die hande van die vors is en dat geen enkele organisasie of liggaam in die nasionale staat kán bestaan sonder die wil of bevel van die vors nie.

In die Zürichse hervorming het Zwingli, die onafhanklike tydgenoot van Luther, grotendeels dieselfde opvattings gehuldig en word die hele gemeenskap, onder die leiding van die burgerlike owerheid, as civitas Dei waardeer. In 'n sekere sin kan gesê word dat by Zwingli die Middeleeuse opvatting van die corpus christianum omvorm word tot die respublica christiana wat dan beperk is tot die territoriale grense van die bepaalde staat (Locher 1979: 171). Die volk en staat in Zürich word as 'n eenheidsgemeenskap waardeer met die burgerlike owerheid as die 
draer van die gesag wat ook ten opsigte van die kerk, die ius reformandi besit. Zwingli stel dan ook: "n Christelike stad is niks anders as 'n Christelike gemeente nie' en in dié stad is die lotgevalle van 'die skape van Christus' in die hande van die magistrate, oftewel die burgerlike owerheidspersone. Inderdaad het die kerk 'n belangrike rol om hier te speel in dié sin dat die kerk die Woord van God óók aan die owerheid moet verkondig, maar die kerk word nié as 'n aparte societas of liggaam wat in eie reg bestaan, waardeer nie (Haas 1969: 216-222). Hier het ons te make, soos Locher (1979: 225) dit stel, met 'n profeties-pneumatiese teokrasie wat deur owerheid en volk nagestreef moet word en waar die owerheid die taak opgelê word om die Reformatoriese geloof en godsdiens te steun en te bevorder. Dit omdat die regsbasis van die Christelike gemeenskap in die Wet van God gegee is. Nieteenstaande Zwingli se vroeë dood vervaag sy opvattings nie, maar word deur sy opvolger, Heinrich Bullinger, voortgesit. Veral by Bullinger word dit duidelik dat sy opvatting oor die respublica christiana wat onder die sorg en gesag van die Christelike owerheid staan, sterk bepaal word deur sy sentrale teologiese leer van die verbond. Vanuit dié verbondsopvatting word die samewerking van profete-stand en owerheid Skriftuurlik geregverdig. Dit was Bullinger se opvatting dat die Christelike magistraat of owerheidsperoon die inhoud van die verbond in die Christelike gemeenskap moet verwerklik, wat dus beteken dat die owerheid die gesag in die respublica christiana is (Baker 1980: xxiii). Om dié opvatting te verstaan, moet daar weer na die tiperende verbondsopvatting in die Zürichse hervorming gekyk word.

\section{DIE ZÜRICHSE VERBONDSOPVATTING}

Die gedagte dat die verbond die hele basis is van die verhouding van God tot die mens, was in die sestiende eeu ' $n$ redelik algemeen aanvaarde opvatting. Zwingli het dié gedagte verder uitgewerk in 'n paar geskrifte en sy mees volledige verbondsopvatting kan gevind word in sy antwoord aan die Wederdoper Hubmaier van 1525 en sy Elenchus of 'Weerlegging van die slimmighede van die Wederdopers' van 1527.

In sy uiteensetting stel Zwingli dat God begin om 'n verbond met Adam te sluit (Gen 3: 15) en dat dié verbond daarna vernuwe is met Noag, Abraham en ten slotte met die hele volk Israel (Eks 19: 5). Elke vernuwing maak die inhoud van die verbond net duideliker. Uiteindelik het Jesus Christus die verbond vervul èn hernuwe sodat daar net één verbond één volk van God, vanaf Adam tot die hede is.

Baie duidelik stel $Z$ wingli die eenheid van die verbond en dit bete- 
ken vir hom óók die essensiële eenheid van die Ou en Nuwe Testament, al was dit dan ook net in soteriologiese sin.

Verder is dit belangrik dat $Z$ wingli die verbond en uitverkiesing aan mekaar koppel. Hoewel dit so is dat slegs die uitverkorenes deel van die verbondsvolk van God kán wees, moet almal wat binne die verbond gebore is, gedoop word en moet hulle as uitverkorenes beskou word totdat God self die teendeel aantoon. Wat Zwingli se opvatting van die gemeenskap betref, is dit duidelik dat hy nooit die selfstandigheid van die kerk as 'n eiesoortige liggaam in die gemeenskap gestel het nie. In Zürich het die kerk, sy orde en inrigting en selfs sy finansiering, bestaan kragtens ' $n$ reëling van die burgerlike owerhede. In die Zürichse gemeenskap is daar net één gesagdraer en dit is die burgerlike owerheid. Hoewel Zwingli 'n groot invloed in die politieke gang van sake in Zürich gehad het en daar selfs van ' $n$ 'Pfaffenregiment' sprake was, was dit nooit 'n geïnstitueerde saak nie en was dit slegs vanweë $Z$ wingli se persoon so gewees.

$Z$ wingli het, grotendeels op grond van sy verbondsleer, ' $n$ situasie geskep waar die kerk deur die owerheid regeer is. Sy argument daarvoor is dat die owerheid regmatiglik deur die volk daargestel is. Omdat die kerklike en politieke gemeenskap dieselfde is, oordeel Zwingli dat die burgerlike owerheid, ook wat die kerk betref, regmatiglik namens die kerklike gemeenskap optree. Omdat die owerheid uiteraard 'n Christelike owerheid is, sien Zwingli hierin geen probleme nie.

Bullinger se opvattings, deels oorspronklik deels teruggaande op dié van Zwingli (Baker 1980: 15 en 18) het die Zürichse verbondsteologie 'n definitiewe beslag gegee. Eiesoortig in Bullinger se opvatting is sy uitgangspunt dat die verbond ' $n$ bilaterale ooreenkoms of verdrag tussen God en mens is. Bullinger se duidelikste uiteensetting van sy verbondsteologie word gevind in sy De testamento seu foedere Dei unico et aeterno van 1534.

Van belang, vir hierdie ondersoek, is slegs die vraag in hoeverre Bullinger se verbondsteologie sy opvattings oor die Zürichse respublica christiana bepaal het. In hierdie verband kan gestel word dat Bullinger die Kerkhervorming sien as ' $n$ herstel van die verbond en daarom is die norm en reël van die verbond, soos dit in die Ou Testament gegee is, ook toepaslik op Zürich se Christelike gemeenskap. Aangesien almal deur die kinderdoop in die verband van die verbond geplaas is, daarom moes die Christelike gemeenskap, die sigbare kerk, die civitas $\mathrm{Dei}$ (wat gelowiges èn ongelowiges insluit) die voorwaardes van die verbond stiptelik nakom. Vir Bullinger is die sigbare kerk dieselfde as 
die burgerlike gemeenskap, omdat dieselfde mense sowel die kerk as die burgerlike gemeenskap vorm. Vir dié gemeenskap is die Ou-Testamentiese situasie die vanselfsprekende model waar die koning gesorg het dat die volk sy verbondsverpligtinge nakom. Volgens Bullinger se opvatting was die magistraat of die burgerlike owerheid dié dienskneg van God, die owerheid van die volk van God wat in 'n Christelike gemeenskap saamgevoeg is. Vir Bullinger is daar nié ' $n$ verskil tussen die burgerlike gemeenskap en die kerk nie. Die kerk was die gemeenskap, die corpus respublica christiana. Sodat mens kan sê dat ons hier 'n soort Protestantse corpus christianum het met die burgerlike owerheid as die gesagdraer wat oor alles, óók die kerk, gesag uitoefen, behalwe oor die verkondiging van die Woord. Vir Bullinger is die Christelike magistraat wat oor die volk van God regeer, 'n Goddelike instelling; dit is die middel waardeur God self sy volk regeer en dáárom moet hy ook oor die sigbare kerk regeer. Sy taak is, breed gesien, om die gemeenskap as ' $n$ verbondsgemeenskap te bewaar en te sorg dat die eise en norme van die verbond nagekom word en dat almal in vroomheid sal lewe.

Vanweë sy siening dat die Christelike gemeenskap 'n eenheid is, dra Bullinger selfs die handhawing van die kerklike dissipline oor aan die burgerlike owerheid, want volgens Bullinger is godsdienstige sowel as ander oortredings openbare misdade en moet dit deur die Christelike magistraat gestraf word ter wille van die behoud van die respublica christiana.

So gesien is die verbond vir Bullinger nie net 'n teologiese leerstuk nie, maar die basis van die reg, die maatskaplike ordening en die persoonlike en maatskaplike etiek. Die verbond is die verbindende element wat die volk van God in ' $n$ Christelike gemeenskap saambind.

In Bullinger se verbondsgemeenskap speel die verkondiger van die Woord ' $n$ baie belangrike rol omdat die Woord die oorsprong èn norm vir die lewe van die mens èn van die gemeenskap is. Alles draai by Bullinger egter om die Christelike magistraat wat deur die predikant deur middel van die prediking gelei sal word.

'n Interessante aspek van Bullinger se opvattings is dat hy feitlik géén beperkings op die magistraat se uitoefening van sy gesag plaas nie. Nêrens het Bullinger so iets soos 'n reg van weerstand teen die magistraat na vore gebring nie en sy opvatting van die gesag van die magistraat is dat dit slegs deur God self beperk kan word. Die prediker van die Woord het nie die moontlikheid om die magistraat te dwing om sy prediking te aanvaar nie en die magistraat word ook nie verplig 
om dit te aanvaar nie. In dié sin het Bullinger, sonder dat hy dit miskien so wou gehad het, 'n bydrae gelewer tot die teorie van die onbeperkte, God-gegewe gesag van die koning. Dit is ' $n$ teorie wat deur die Protestant, Thomas Erastus, en die Rooms-Katoliek, Jean Bodin, verder uitgewerk word.

Bullinger handhaaf, ten slotte, ook nog die Middeleeuse gedagte dat die godsdiens 'n voorwaarde vir die eenheid van die gemeenskap is. Die Zürichse respublica christiana verdra nie godsdienstige verskille nie, soos die stryd met die Anabaptiste duidelik aantoon. Godsdienstige afwyking kan nie verdra word binne die gemeenskap nie en daarom word die afwykendes uitgewerp.

Die eerste stap in die rigting van godsdienstige verdraagsaamheid is die formulering in Augsburg 1555 van die cuius regio eius religio-beginsel waardeur 'n soort internasionaal godsdienstige verdraagsaamheid geproklameer word. Daarmee word gestel dat godsdienstige eenheid nie ' $n$ bestaansvoorwaarde vir die Heilige Romeinse Ryk van die Duitse Volk is nie. Dit is veral Jean Bodin (1580-1596) wat die godsdiens nie meer die basis van die bestaan van die staat maak nie, maar dit tot 'n private aangeleentheid degradeer.

Dit is in hierdie tyd wat Thomas Erastus lewe en sy bydrae maak wat nie onbelangrik was nie.

\section{ENKELE BIOGRAFIESE GEGEWENS OOR ERASTUS}

Thomas Erastus (1520-1583) gebore in Baden, geleë in die Aargaustreek, het waarskynlik sy eerste skoolopvoeding in Zürich gehad en daarna het hy Teologie in Basel bestudeer en Filosofie en Geneeskunde te Bologna en Padua in Italië. In 1558 word hy die persoonlike geneesheer van Keurvors Otto Heinrich van die Pfalz en terselfdertyd hoogleraar in die Geneeskunde aan die Universiteit van Heidelberg. Keurvors Friedrich III het Erastus as lid van die Kirchenrath benoem en in dié hoedanigheid het hy deelgeneem aan godsdiensgesprekke tussen die Heidelbergers en Lutherane in 1560 en 1564.

Onder die regering van Friedrich III het Erastus 'n groot bydrae gelewer om die Calvinistiese kerk te orden en as kerkraadslid was hy midde-in die probleme. Roth (1954: 20) wys daarop dat Erastus nie alleen vanweë sy kennis van die teologie nie, maar veral vanweë sy aangebore diplomatieke vermoëns dié leidinggewende kerklike figuur in die Pfalz geword het. Hy bly aan as professor na die dood van Friedrich III, maar toe daar van hom verwag is om ook die Lutherse 
belydenisskrifte te onderteken, lê hy sy amp neer. Sy laaste lewensjare slyt hy in Basel waar hy ook begrawe is. Gedurende Erastus se professoraat wou die Calviniste in Heidelberg, na die voorbeeld van Genève, die handhawing en uitoefening van die kerklike tug in die hande van die kerkraad lê. Erastus, wat in hierdie sake, sterk deur die Zürichse opvattings beïnvloed was, het dit teengestaan. Sy geskrif Explicatio gravissimae quaestionis utrum excommunicatio het hy in die jare 1568-69 opgestel, hoewel dit eers in 1589 verskyn het. Interessant is dat hierdie werk hoofsaaklik 'n teologiese inslag het en feitlik geen juridiese of staatsregtelike argumente gebruik nie, hoewel dit oor die inrigting van die staat èn die kerk handel.

In hierdie strydskrif van Erastus, wat gerig is téén die Calvinistiese opvatting dat die dissipline, tug èn die ban onder die opdrag en werksaamhede van die Kerkraad ressorteer, begin Erastus om sowel die ban èn die kerkbegrip te omskrywe. Dan betoog hy dat sowel in die $\mathrm{Ou}$ Testament as in die Nuwe Testament die kerklike ban nie bestaan nie, maar slegs die owerheidsgesag wat oor alle oortredings regspreek. Erastus beroep hom in sy argumentering baie sterk op die voorbeeld van die Ou-Testamentiese inrigting van die gemeenskap omdat dit sy opvattings die sterkste steun. Dit is in hierdie deel van die argument wat Erastus sy visie van die owerheid en die posisie van die kerk in die gemeenskap gee.

Hoewel Erastus volledig die teologie wat in die Pfalz geld, soos uitgedruk in die Heidelbergse Kategismus en die kerklike orde aanvaar, is hy in die saak van die ban oortuig dat die hele verhouding van owerheid en kerk hier ter sake is. Vir Erastus is dit belangrik om hier die posisie en plek van die owerheid met teologiese argumente te regverdig (Roth 1954: 94-95). Dit is duidelik dat Erastus se siening, hoewel dit op kleiner punte van die Zürichse opvattings verskil, grotendeels op daardie opvattings gebou is. Dit blyk uit sy argumente èn sy gebruik van Wolfgang Musculus van Bern se Loci communes waarin 'n hele hoofstuk, de magistratu, voorkom (vgl Roth 1954: 107).

\section{ERASTUS SE OPVATTINGS OOR OWERHEID, GEMEENSKAP EN KERK}

Erastus sien die gemeenskap of volk in 'n bepaalde land as 'n eenheid. Die volk het, in Erastus se opvattings egter géén selfstandige politieke rol nie. Dié hele volk of gemeenskap kom egter wel na vore omdat die gemeenskap deur die kerk omvat word. 
Wat die kerk betref, onderskei Erastus baie duidelik 'n regnum spirituale Dei, 'n onsigbare kerk wat die ware kerk is. Dááraan kry die mens alleen deur die genade van God deel. Dié genade ontvang die mens alleen deur die ware geloof wat God self, deur die Heilige Gees, in die hart van die mens bewerk. Indien 'n mens, deur die geloof deel het aan die genade, dan is hy daarmee terselfdertyd geroep tot en deelgenoot van die gemeenskap met Christus. Hierdie gemeenskap van geroepenes, heiliges, word nié in die wêreld sigbaar nie, want dit bestaan alléén in die harte van die gelowiges.

Hierdie onsigbare kerk bestaan binne die ecclesia externa. Lidmaatskap van die uiterlike kerk word bepaal deur die vraag of 'n mens geloofsbelydenis afgelê het, die leer van die kerk as waar aanvaar en die sakramente ontvang het. Elkeen wat bereid is om aan dié voorwaardes te voldoen, mag nie uit die societas fidelium externa seu visibilis uitgesluit word nie.

Hierdie sigbare kerk staan in diens van God en het die taak om die lidmate deur die prediking van die Woord en die uitdeel van die sakramente te lei na die innerlike gemeenskap met Christus. Tog is dit slegs God self wat die mens tot Hom kan trek, kan uitverkies en sy genade skenk. Dié sigbare kerk bly egter 'n formele, uiterlike liggaam solank God nie sy Gees stuur om dáár werksaam te wees nie. Daarom sien Erastus die uiterlike kerk as bloot 'n uiterlik-wêreldlike organisasie, al is dit so dat die doel van die kerk verder as hierdie wêreld lê. Omdat die kerk maar só 'n uiterlike organisasie is, staan dié kerk volledig onder die gesag van die wêreldlik-burgerlike owerheid wat die opdrag van God ontvang het om in die wêreld te regeer. Erastus se argument téén die hantering van die kerklike tug en ban is dat die kerkraad in ieder geval nie diegene wat tot die regnum spirituale Dei behoort, met die ban uit die gemeenskap met Christus kan verdryf nie, aangesien die kerkraad slegs oor uiterlike sake kan oordeel.

Ook ten opsigte van die hantering van die tug en die ban met betrekking tot die lede van die ecclesia externa is Erastus van mening dat dit onskriftuurlik is. As dit die taak van die kerk is om die lede van die ecclesia externa voor te berei en na die onsigbare gemeenskap met Christus te lei, dan verydel die kerk juis sy doel deur die sondaars uit die kerk te weer. Buitendien, argumenteer hy, is die mens 'n sondaar en dit kan beteken dat deur die ban méér mense buite die sigbare kerk sal beland as wat daarin is.

Hier word dit duidelik dat die Zürichse verbondsopvatting ' $n$ beslissende rol speel in Erastus se siening van die uiterlike kerk wat die hele 
gemeenskap omvat. Dié gemeenskap kan, volgens Erastus, net één hoof hê en dit is die burgerlike owerheid, of wel die pius magistratus. Vir Erastus is die presiese vorm van die owerheid of die struktuur van die gemeenskap nie so belangrik nie, solank die hoogste en finale gesag in die hande van die magistraat of owerheid lê. Dié gesag strek hom oor die hele lewe, burgerlik sowel as kerklik, uit. Hierdie konsentrasie van alle mag en gesag in die hande van die owerheid regverdig Erastus deur te verwys na die Ou-Testamentiese koningskap. Die instelling daarvan, is vir Erastus die norm en reël vir die Christelike owerheid en die gemeenskapsorde.

Die sigbare kerk val vir Erastus ook onder die gesag van die owerheid net soos, byvoorbeeld, die universiteit. Die taak van die owerheid ten opsigte van die kerk is die oprigting en handhawing van die uiterlike organisasie, die uitoefening van die kerklike tug en die sorg vir en instandhouding van die ware leer. Dit is, uit die aard van die saak, nié nodig dat die pius magistratus dit alles in eie persoon sal hanteer nie. Hy kan daarvoor verskillende van sy bevoegdhede delegeer, maar dit moet vasstaan dat hy dié gesag uitoefen. Ten opsigte van die handhawing van die kerklike dissipline en tug stel Erastus dat dit die owerheid se plig is om toe te sien dat die kerklike ampsdraers hulle plig nakom, want die ampsdraer is gehoorsaamheid aan God en die owerheid verskuldig.

Die sorg vir die regskape lewe van die lidmate moet deur die openbare gesagshowe hanteer word, want dit is géén besondere opdrag wat aan die kerk gegee is nie. Vir die opsig oor die lewe van die lidmate kan die owerheid ' $n$ liggaam van eerbare manne in die lewe roep om hom hierin by te staan. Die hantering van ketters en hulle verbanning uit die Christelike gemeenskap sien Erastus, in navolging van Luther, as 'n saak van die burgerlike polisie, want dit gaan hier om die beskerming van die Christelike gemeenskap. Hieruit blyk dat Erastus, net soos Zwingli en Bullinger, die gedagte van godsdienstige verdraagsaamheid nie ken nie. In die Christelike gemeenskap kan net die ware godsdiens bestaan en omdat dit ' $n$ publieke aangeleentheid is, kan géén afwykende mening geduld word nie. Op dié manier word die kerklike organisasie, en die leer en lewe van die lidmate, volledig aan die owerheid onderwerp. Slegs die verkondiging van die Woord en die uitdeel van die sakramente staan buite die bevoegdheid van die owerheid. Die owerheid moet egter toesien dat hierdie vryheid voortdurend gehandhaaf word. Die gesag wat die owerheid oor die kerk het, is nie 'n willekeurige gesag nie. Inteendeel, die owerheid is verplig om hom 
streng by die reël en voorskrif van die Skrif te hou. Dit is veral hiér wat die amp van die predikant so belangrik is, want hy moet die owerheid ex verbo Dei vermaan en lei ten opsigte van sy plig. Die pius magistratus sal, volgens Erastus, hom vanselfsprekend deur die Woord van God laat lei, want die owerheid het van God self sy diens ontvang en is daarom aan God verantwoording verskuldig. Uiteraard het die owerheid nie 'n onbeperkte gesag oor die kerk nie. Die grense van die owerheid se gesag word deur die Wet van God self getrek. Juis omdat die mens 'n mens is, is hy absoluut gebind deur die norm en reël wat die Woord gee. Dit beteken dat die owerheid die reël van die aequitas, iustitia en honestas nié mag oortree nie. Deur dit te stel, betoog Erastus dat die goddelike reg, soos in die dekaloog gegee, saamval met die natuurlike reg wat in die gemeenskap geld. Juis in hierdie deel van sy betoog, sluit Erastus nou by Bullinger en die Switserse opvattings aan.

Met hierdie uiteensetting poneer Erastus ' $n$ teokratiese gemeenskapsorde wat volkome onderwerp is aan die gesag van die pius magistratus wat op sy beurt weer volkome aan die goddelike reg en die Woord van God gebind is. Deur alle gesag aan die burgerlike owerheid te gee, wil Erastus vermy dat die kerk as selfstandige grootheid teenoor die owerheid sal staan of die owerheid se gesag sal ondergrawe. Waarskynlik vanweë sy ervarings in Heidelberg het Erastus baie meer vertroue in ' $n$ Christelike owerheid as in die kerklike ampte en regeervergaderings. Deur baie duidelik te onderskei tussen die uiterlike, sigbare kerklike organisasie wat ' $n$ vanselfsprekende faset van die Christelike gemeenskap of volk is en die onsigbare koninkryk van God wat direk aan Christus verbonde is, vermy Erastus ook die gevaar dat die owerheid as hoof van die kerk Jesus Christus as sodanig sou verdring.

Dit is duidelik dat Erastus, net soos die Zürichse teoloë, die bestaansmoontlikheid van 'n omvattende corpus christianum, soos die Middeleeue dit geken het, verwerp. Die verskeidenheid van plek, tyd en volk is hier belangriker en daarom word die bestaan van verskillende, onafhanklike, nasionaal-bepaalde kerklike organisasies as vanselfsprekend aanvaar. Daarby maak Zürich en Erastus se standpunt dat die nasionale kerk vanself 'n staatskerk sal wees, so 'n opvatting ook verpligtend. Op grond van hulle siening van die verbond en die sentrale posisie wat dit inneem, kan hulle die sigbare kerk nie as ' $n$ aparte corpus of societas in die Christelike gemeenskap aanvaar nie.

Met sy uiteensetting het Erastus in sy siening van die respublica christiana die Zürichse siening, wat op die model van die verbond gebou is, 'n stap verder gevoer. Die absolute gesag van die pius magis- 
tratus is naamlik neergelê en is die kerk as staatskerk, in 'n afhanklike posisie van die owerheid, geplaas. Daarmee staan Erastus, met sy Protestants-teologiese argumente, in feite op dieselfde standpunt as die Roomse Bodinus met sy staatsregtelik-filosofiese argument vir die absolute gesag van die vors-owerheid. Dié Erastiaanse siening wat duidelik teenoor die standpunt van Calvyn en Beza staan, was die eindproduk van die Zürichse denke oor verbond, owerheid, gemeenskap en kerk.

\section{SLOTOPMERKING}

Die invloed van Erastus se denke het veral in die Engelse ecclesia Anglicana deurgewerk. Erastus se werk, Explicatio gravissimae, is eers in 1589 , ses jaar na sy dood gepubliseer. In 1590 het Theodorus Beza in sy Tractatus pius et moderatus de vera excommunicatio et Christiano Presbyterio die aandag op Erastus se werk gevestig deur sy opvattings, vanuit die Calvinistiese standpunt, te weerlê. Erastus se opvattings is in Engeland veral gepopulariseer deur John Whitgift, die aartsbiskop van Canterbury, één van die belangrikste Elizabethse biskoppe. Die Erastianisme as aanduiding van 'n leer waarvolgens die kerk geen selfstandigheid in die Christelike gemeenskap het nie, wat deur die pius magistratus regeer word, het in die Engelse en Skotse kerkgeskiedenis 'n vaste begrip geword.

So het die Zürichse opvatting in hierdie verband nog 'n merkwaardige nawerking in die kerkgeskiedenis gehad, afgesien daarvan dat dit ook ' $n$ bydrae tot die staatsregtelike teorie van die staatsabsolutisme en die goddelike reg van die vors gelewer het.

\section{Literatuurverwysings}

BAKER, JW 1980. Heinrich Bullinger and the covenant: The other Reformed Tradition. Chico: Ohio University Press.

ERASTUS, T 1589. Explicatio gravissimae quaestionis utrum excommunicatio, quatenus relig. ionem intelligentes et amplexantes a sacramentorum usu propter admissum facinus arcet, mandato nitatur divino, an excognita sit ab hominibus.

FREMANTLE, A 1963. The papal encyclicals in their historical context. New York. (MentorOmega Books.)

GILES, E 1952. Documents illustrating papal authority, AD 96-454. London: SPCK.

HAAS, M 1969. Huldrych Zwingli und seine Zeit. Zurich: Zwingli Verlag.

KOCH, E 1968. Die Theologie der Confessio Helvetica Posterior. Neukirchen-Vluyn: Neukirchener Verlag.

KOHLER, W 1952. Huldrych Zwingli, Stuttgart: Koehter. 
LOCHER, GW 1979. Die Zwinglische Reformation im Rahmen der europäischen Kirchengeschichte. Gottingen: Vandenhoeck und Ruprecht.

PFISTER, R 1942. Zwingli der Staatsmann. Zürich: Zwingli Verlag.

WESEL-ROTH, R 1954. Thomas Erastus. Lahr-Baden: Schauenburg.

SCHMIDT-CLAUSING, F 1965. Zwingli. Berlin: Walter de Gruyter.

SCHAFF, P 1909. The Creeds of Christendom, Vol III, New York: Harper \& Brothers.

VAN DER LINDE, H 1948. Rome en de Una Sancta, Nijkerk: Callenbach. 